\title{
Rheology of THF hydrate slurries at high pressure
}

\author{
Paulo H. de Lima Silva ${ }^{1}$, Mônica F. Naccache ${ }^{1, *}$, Paulo R. de Souza Mendes ${ }^{1}$, Adriana Teixeira ${ }^{2}$, and Leandro S. Valim ${ }^{2}$ \\ ${ }^{1}$ Department of Mechanical Engineering, Pontifícia Universidade Católica do Rio de Janeiro, Rio de Janeiro, RJ 22451-900, Brazil \\ ${ }^{2}$ Petrobras Research Center (CENPES), Petrobras, Rio de Janeiro, RJ 21941-598, Brazil
}

Received: 1 November 2019 / Accepted: 28 January 2020

\begin{abstract}
One of the main issues in the area of drilling and production in deep and ultra-deep water in the oil industry is the formation of natural gas hydrates. Hydrates are crystalline structures resembling ice, which are usually formed in conditions of high pressure and low temperature. Once these structures are formed, they can grow and agglomerate, forming plugs that can eventually completely or partially block the production lines, causing huge financial losses. To predict flow behavior of these fluids inside the production lines, it is necessary to understand their mechanical behavior. This work analyzes the rheological behavior of hydrates slurries formed by a mixture of water and Tetrahydrofuran (THF) under high pressure and low temperature conditions, close to the ones found in deep water oil exploration. The THF hydrates form similar structures as the hydrates originally formed in the water-in-oil emulsions in the presence of natural gas, at extreme conditions of high pressure and low temperature. The experiments revealed some important issues that need to be taken into account in the rheological measurements. The results obtained show that the hydrate slurry viscosity increases with pressure. Oscillatory tests showed that elasticity and yield stress also increase with pressure.
\end{abstract}

\section{Introduction}

Natural gas hydrates are solid, crystalline structures that looks like ice [1,2], which are formed under extreme thermodynamic conditions of high pressure and low temperature [1-4]. Natural gas hydrates are a major concern of the oil industry, since their formation can deeply affect the flow during drilling and production $[5,6]$. However, it is worth mentioning that hydrates can be used for some good purposes. For instance, they are very effective when used for gas storage, and seem to be a future potential energy source [7-15].

Hydrates formation is affected not only by pressure and temperature, but also by several other variables such as fluid composition, flow rate/turbulence, contact surface between liquid and gas, and water salinity [16]. Therefore, when the production lines or the wells are inside the hydrates formation envelope of high pressure and low temperature, it is imperative to know how all these variables will affect hydrates formation and agglomeration, in order to control and optimize the production and/or drilling operations [3, 17, 18]. Yao et al. [19] performed a numerical study of the flow of hydrate slurries through inclined pipelines. The results show that larger pipe inclination and larger flow rates lead to more homogeneous distributions of hydrate particles size and concentration, which

\footnotetext{
* Corresponding author: naccache@puc-rio.br
}

favor the slurry transportation and reduce the risk of blocking the pipeline. The initial size of hydrate particles is also an important parameter since larger particles seem to agglomerate more increasing the slurry heterogeneities, and harming the slurry transportation. The hydrate dissociation process was analyzed numerically by [20], which showed that the wellbore pressure can be controlled to improve the dissociation rate, but this effect depends on the reservoir and hydrate properties.

It is also important to understand how these processes begin and develop, and what can be done to avoid, delay, or minimize it. The induction time, or the time taken to appear the first hydrate crystals, was determined experimentally in a flow loop by Lv et al. [21], and the effects of several parameters were investigated. The results showed that the induction time decreases as supercooling increases, similar to what happens in autoclave systems. For low flow rates the induction times decrease as the flow rate increases, but the reverse trend is observed after a critical value of flow rate. The authors observed the same behavior increasing the water cut.

There are several ways that can be used to prevent hydrates formation or agglomeration. The first tentative would be to avoid the hydrate formation thermodynamic envelope, by heating or thermal insulating the production lines, or reducing pressure. In addition, the injection of thermodynamic inhibitors, kinetic inhibitors, and/or antiagglomeration agents are commonly used in the industry to reduce hydrate formation and growth [1, 3, 21-24]. 
This study analyzes the rheology of hydrate slurries formed from a model fluid composed of deionized water and Tetrahydrofuran (THF), in similar conditions to the ones obtained at deep water oil fields, i.e. high pressure and low temperature. This model fluid forms hydrates structure of type II, which are similar of that formed when a gas is present in water-in-oil emulsions. Moreover, THF is soluble in water and is in the liquid state at atmospheric pressure so that the model is easier to work with, giving faster, and reliable results [25]. The THF miscibility in water also eliminates the problem of diffusion resistance during hydrate formation [26, 27].

Previous studies in the literature show that the process of THF-hydrates formation is exothermic, and the resulting hydrate slurry presents a non-Newtonian shear-thinning behavior [28-30]. In addition, the process of hydrates formation presents a strong dependence on fluid temperature and agitation [28, 31-33]. When hydrates are formed in pressurized and monitored systems the pressure varies during the formation, as well as temperature while the gas is being consumed [33].

Li et al. [34] show in their study that while the hydrate slurry is formed, a constant pressure plateau is reached shortly after the hydrates formation, but during the process the pressure gradually decreases. Qin et al. [35] found that shear rate is a key factor in the formation of hydrates in water-in-oil emulsion systems using methane as a hydrateforming gas. An abrupt increase of the viscosity of such systems was observed in an isochoric process as the gas was being consumed, leading to a decrease in pressure values.

Ahuja et al. [36] compare the water-in-oil and cyclopentane emulsions in the oil phase as a hydrate former. They used propane to pressurize the system and form hydrates. Large differences in the viscosity and yield stress of the final structure were observed between emulsions formed with cyclopentane and propane. The hydrate slurries show shear-thinning behavior, but the shear-thinning behavior of the hydrate slurry with cyclopentane is stronger, and values of viscosity and yield stress higher.

The present work is organized as follow. The next section presents the materials and methods used to obtain the high pressure rheology of the THF-hydrates slurries. The first step was to delimit the area of operation of the pressure cell used in the measurements. Preliminary tests are performed to check the minimum and maximum torques to obtain reliable results, and the test temperature. Preliminary rheological tests are described in the following section. Finally, in the last two section the rheological results are presented and discussed, and some final remarks are presented.

\section{Materials and methods}

The samples were prepared with a mixture of water and tetrahydrofuran. We used deionized water obtained from a reverse osmosis system, model OS10 LX manufactured by Gehaka, and tetrahydrofuran (THF-C4H8O) produced by Sigma-Aldrich with concentration above 99\%, molecular

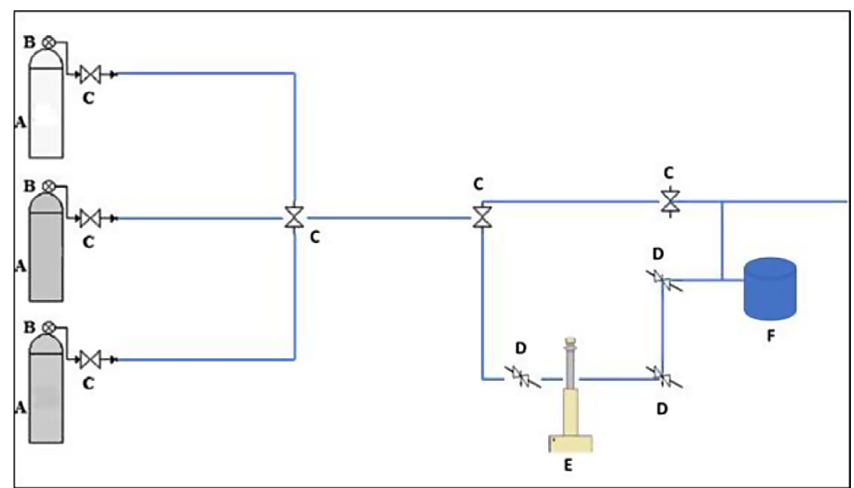

Fig. 1. Schematic of the pressurizing system: (A) cylinder of gases; (B) regulating valve; (C) globe valve; (D) needle valve; (E) syringe pump; (F) pressure cell.

weight $72.11 \mathrm{~g} / \mathrm{mol}$, density $0.89 \mathrm{~g} / \mathrm{cm}^{3}$, and kinematic viscosity $0.512 \mathrm{~mm}^{2} / \mathrm{s}$ at $25^{\circ} \mathrm{C}\left(77^{\circ} \mathrm{F}\right)$.

Due to its solubility in water, THF was added directly into the water, and the mixture stirred slightly until homogenization. Mixtures were obtained with three concentrations of THF by mass, namely $30 \%, 40 \%$, and $50 \%$ of the sample total weight. These values were chosen based on the fact that the theoretical concentration of THF that would be fully encapsulated by water is $1 \mathrm{~mol}$ of THF to 17 moles of water [37], which is equivalent to a THF weight concentration of $19 \%$ by mass. Hence, for the three concentrations, after hydrate is formed, all water is consumed and some excess THF is expected, forming a slurry where the continuous phase is THF.

A semi-analytical balance, with two precision decimal digits, model BG4400, manufactured by Gehaka, was used to weigh the components. The solutions were stored in $100 \mathrm{~mL}$ closed bottles for later use in rheological tests. To transfer the samples to the measurement site, an Arti Glass syringe with the capacity of $20 \mathrm{~mL}$ of fluid was used.

A pressurized system was developed for the rheological tests performed under pressure, as shown in Figure 1. The circuit was assembled with a valve system through which the gas was injected and purged to/from the syringe pump. The syringe pump was connected to the pressure cell of the rheometer using a gas hose with quick couplings in the tip, which was able to support the traction and the large number of maneuvers that were necessary to be performed during the tests. The gas hose used supports a maximum pressure of 11000 psi (758.4 bar).

Three types of valves were used: needle, globe, and regulator. Globe-type valves allow or block the passage of gases to the internal valves. A single circuit was designed to supply the syringe pump. A regulating valve was positioned at the exit of the cylinders, which measures the gauge pressure of the cylinders and regulates the gas passage to the other side of the line until a pressure up to 15 bar. The needle-type valve feeds the pump and the pressure cell of the rheometer. Also, a needle valve was positioned between the syringe pump and the rheometer to eliminate the gases after the tests, using a pressure line that was added after the globe valve. A syringe-type pump has 
Table 1. Parameters of the concentric cylinders PZ 37.

\begin{tabular}{lc}
\hline Inertia $\left(\mathrm{kg} \mathrm{m}^{2} \times 10^{-6}\right)$ & 66.7 \\
Mass & 421 \\
Material & Titanium \\
Radius & $18.5 \mathrm{~mm}$ \\
Height & $80 \mathrm{~mm}$ \\
\hline
\end{tabular}

been chosen for the system pressurization. The syringe pump used is manufactured by Teledyne Isco, model $260 \mathrm{D}$, and reaches the maximum pressure of $7500 \mathrm{psi}$ (517 bar) with a volumetric capacity of $266 \mathrm{~mL}$.

The rheometer used was the Haake Mars III, from Thermo Fisher Scientific, with a pressure cell model D400, which is able to perform tests up to 400 bar (or 5800 psi). The sample volume is approximately $37 \mathrm{~mL}$. A thermostatic bath model F-25 ME (Julabo), with a mixture of water and monoethyleneglycol, was used to keep temperatures below $0{ }^{\circ} \mathrm{C}$, because the pressure cell does not have a temperature control system. The geometry used in the pressure cell was the smooth concentric cylinders type PZ37, provided by Thermo Fischer Scientific, with the parameters given in Table 1.

\section{Calibration tests}

Some preliminary tests were performed to calibrate the pressure cell. The first calibration test is to define the optimal gap between the pressure cell cover and the magnetic coupling of the geometry. The optimal axial gap may be different for each pressure cell configuration and may change during the period of use, due to thermal and mechanical effects.

An axial ramp test was performed to obtain the optimal gap, which was chosen as the one that gives the minimum value of the Normal Force $\left(F_{N}\right)$. The results obtained are shown in Figure 2. It can be observed that between 3 and $4 \mathrm{~mm}$ the normal force reaches the lowest value. The optimal gap chosen was equal to $3.4 \mathrm{~mm}$, where measurements were more stable and less noisy.

The second calibration performed was the Micro Stress Control (MSC) test. This test was performed to take into account the friction variation of the mechanical bearing of the pressure cell during each revolution, due to its mechanical microscopic imperfections. This variation may result in a periodic data noise for low viscous samples. The angular friction depends on the static position of the mechanical bearing of the pressure cell, and can be determined using the MSC routine in the rheometer program and automatically compensated by it.

The inner magnet must be mounted on the rotor and the rotor must be mounted on the pressure cell with the bearings properly lubricated. For MSC calibration, the pressure cell must be empty, i.e. it must not be filled with a sample.

The MSC calibration is performed using a very low angular velocity. The friction of the bearing measured with

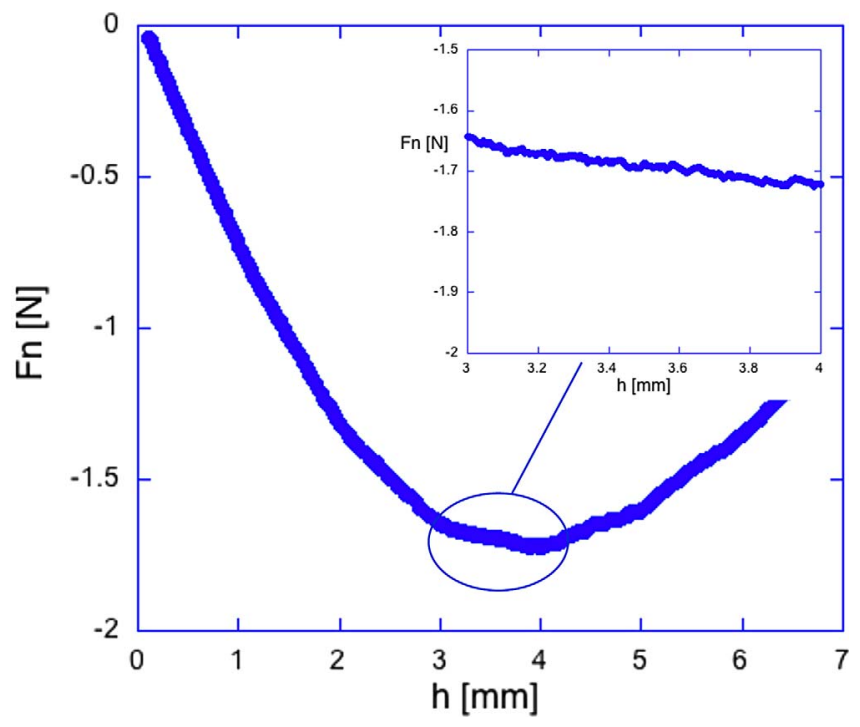

Fig. 2. Normal force as a function of the gap between the pressure cell cover and the magnetic coupling.

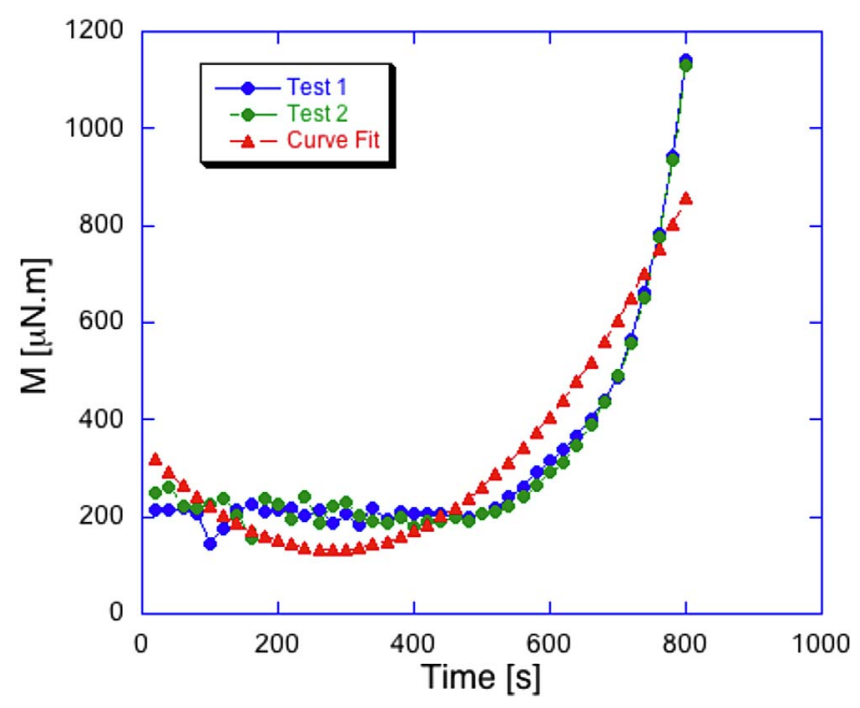

Fig. 3. Torque versus time in MSC test: experimental data and curve fit.

the MSC calibration is related to the static friction at rest, which is the dominant friction at very low angular velocities. For higher angular velocities, dynamic friction becomes the dominant part.

Figure 3 shows the results of the tests performed with water on the sapphire bearings. A curve fit function needs to be defined, which is provided by the rheometer's data analysis program, and its square function parameters are given by: $a=0.0027 ; b=-1.521$; and $c=347.5$. The test results are represented by the Torque (M) curve as a function of time. The fit made with the above parameters is represented in Figure 3 as "Curve Fit", with $R^{2}=0.9211$. Then, the parameter values are entered in the rheometer prior to the tests. 


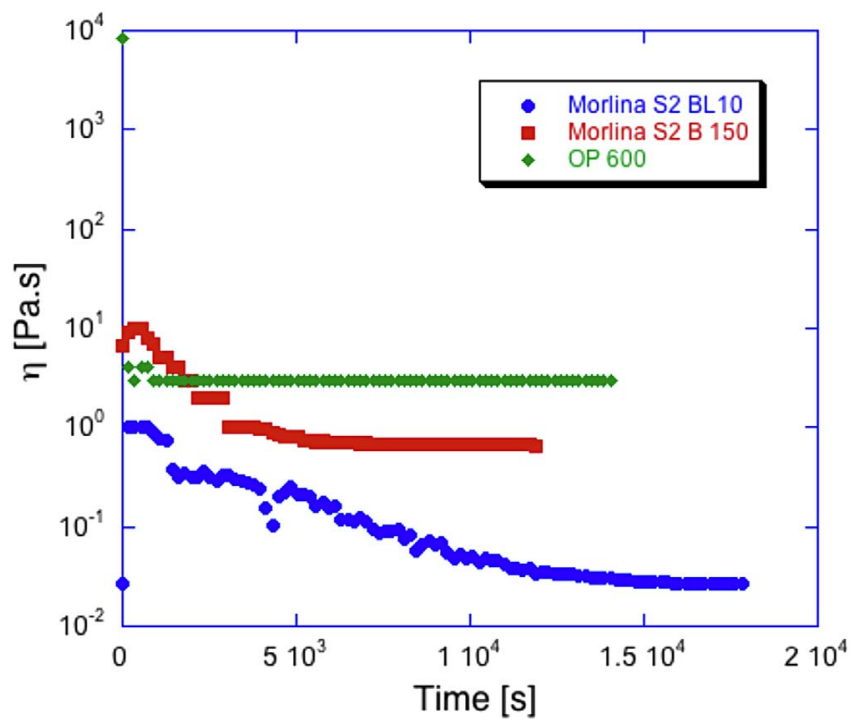

Fig. 4. Viscosity of oils as a function of time. Tests at atmospheric pressure.

After the initial calibrations, an introductory test was performed to verify the minimum torque value for the rheological tests with THF and water. Three oils were used: Shell Morlina S2 BL 10, Shell Morlina S2 B 150, and OP 600 (a standard oil used in the laboratory). Figure 4 presents the results of the flow curve tests for these oils. The tests were performed at a temperature of $20^{\circ} \mathrm{C}$, for a shear rate range from $1 \mathrm{~s}^{-1}$ to $100 \mathrm{~s}^{-1}$. The oils exhibit a Newtonian behavior, as expected, converging to a constant viscosity value over time. The great difficulty in obtaining the constant viscosity value for Shell Morlina S2 BL10 is due to its low viscosity of $0.02 \mathrm{~Pa}$ s at $20^{\circ} \mathrm{C}$.

A very important information derived from these tests is the minimum reliable torque measurement. This torque is the one that will be effectively transferred by the magnetic coupling to the geometry and fluid inside the pressure cell. Thus, the results obtained showed that the minimum torque value for reliable measurements was around $800 \mu \mathrm{Nm}$.

Prior tests were also made to define the time for temperature stabilization inside the pressure cell. It is worth mention that the temperature control on the pressure cell is not available. Thus, a thermostatic bath was used to maintain the internal temperature of the pressure cell at $1{ }^{\circ} \mathrm{C}$. A water and monoethyleneglycol 9:1 ratio mixture, respectively, was used in the bath to prevent the fluid from freezing in the bath and/or circulation hoses by using temperatures below $0{ }^{\circ} \mathrm{C}$. All tests on the pressure cell were performed at constant volume.

Figure 5 shows the temperature within the pressure cell as a function of time. The temperature selected in the thermostatic bath was equal to $-0.6{ }^{\circ} \mathrm{C}$, providing a temperature inside the pressure cell at the end of the test equal to $1{ }^{\circ} \mathrm{C} \pm 0.1{ }^{\circ} \mathrm{C}$. Initially, the sample was at $22{ }^{\circ} \mathrm{C}$ and the temperature decays as the bath temperature decreased, stabilizing after $80 \mathrm{~min}$. Then, all the tests were performed after the samples underwent a thermal stabilization step of $90 \mathrm{~min}$.

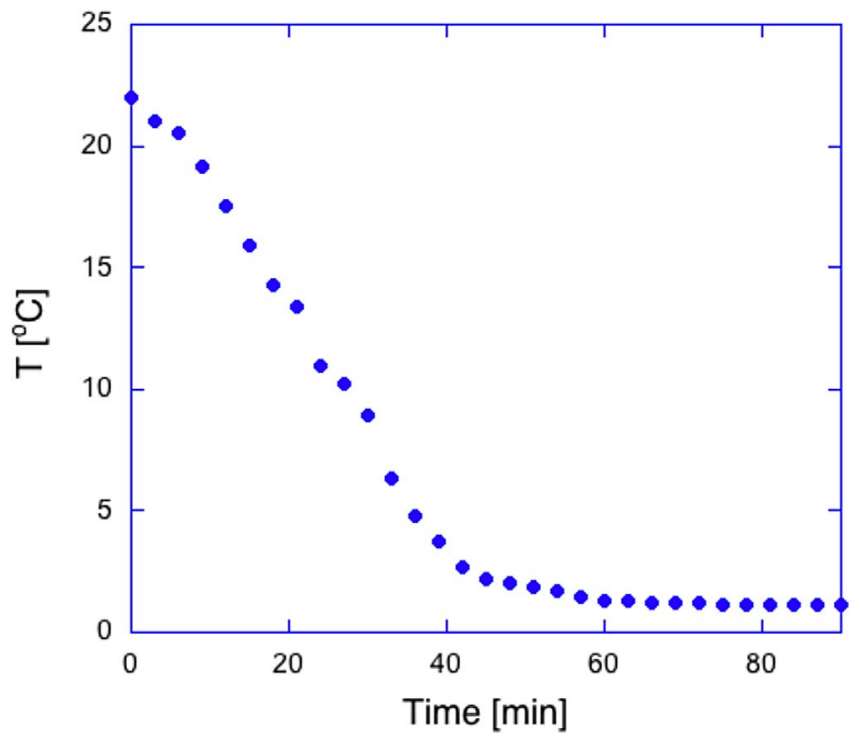

Fig. 5. Temperature versus time in the pressure cell.

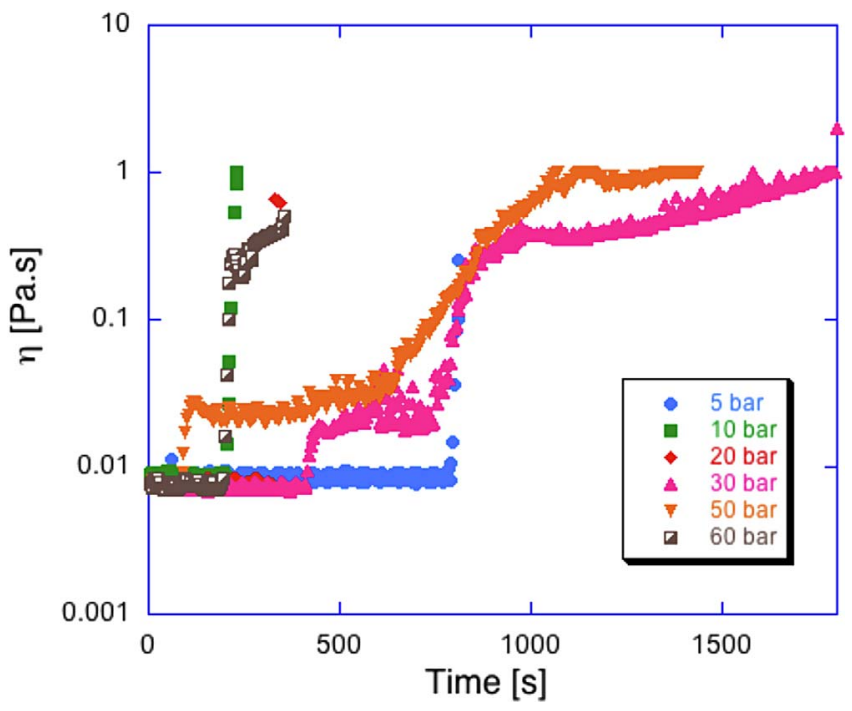

Fig. 6. Viscosity versus time for constant shear rate test $\left(\dot{\gamma}=300 \mathrm{~s}^{-1}\right)$ for $30 \%$ wt of THF, and pressure range of 5-60 bar.

\section{Results and discussion}

THF hydrate slurries tests were performed for concentrations of $30 \%, 40 \%$, and $50 \%$ of THF by mass. The first rheological tests performed were the constant shear rate tests. The shear rate was set equal to $300 \mathrm{~s}^{-1}$, chosen to avoid wall slip effects, and in addition to provide larger torque values, to guarantee that we would be above the minimum reliable torque value. It should be noted that the geometry used has a smooth wall, so wall slip could be an issue.

Figure 6 shows the results of viscosity versus time for the concentration of $30 \%$ THF by mass. The gas used to pressurize the system was nitrogen, provided by White 
Martins, with grade 4.6 , that is, with a minimum purity of $99.996 \%$.

The results show that in the beginning of the tests, the fluid viscosity is around $0.01 \mathrm{~Pa} \mathrm{~s}$, because no hydrates were formed. After some critical time, which is a function of the pressure, it is noted an abrupt increase of the viscosity that is related to the beginning of the formation of the hydrates crystals that, combined with the water + THF, will result in the hydrate slurry. The viscosity tends to reach a high level plateau. However, it is noted that this plateau is reached only in some cases. This is due to the fact that the slurries formed presented higher viscosity values that end up reaching a maximum torque limit of the equipment, above which the torque was no longer transmitted to the internal coupling. So, the highest viscosity values shown in the plot are not real values of the fluids viscosity, but only maximum values that could be obtained from the equipment. After this maximum torque, the outer coupling began to slide, causing the measurements to drop and vary. The average maximum torque value that the pressure cell in its internal coupling is capable of receiving by the external coupling was around $70000 \mu \mathrm{Nm}$. It is also important to note that the steady state regime was not achieved in any of the situations showed in this plot. The results also indicate that the higher the pressure the faster the hydrate formation process occurs, the exception was at 10 bar pressure, where hydrate formation occurred as fast as 60 bar pressure. Since the process of hydrate formation is highly unstable, any perturbation can affect the process, therefore the faster formation for the 10 bar case could be explained by some unknown perturbation that could have occurred in the test.

Figure 7 shows a picture of the $30 \%$ wt of THF mixtures and nitrogen hydrates, formed in the pressure cell at 30 bar. The structure formed is a cohesive and whitish block, and nitrogen bubbles are observed emerging as the structure dissolves. One possible reason for this type of structure is because there is space available when water molecules form the cages to trap the THF. So, the small $\mathrm{N}_{2}$ gas molecules tend to fill the smaller cavities and help forming the hydrate structure type II [36].

Since we could not obtain the pressurized rheological data using the hydrates slurries obtained with the mixture with $30 \%$ wt of THF, due to the upper torque limit of the magnetic coupling between the rheometer and the pressure cell, we decided to increase the THF concentration to form less viscous hydrates slurries (see [28]). Then, tests with $40 \%$ wt of THF were performed in order to obtain a less viscous slurry, with larger crystals dispersion. The test conditions were the same as the ones used with the mixtures with $30 \%$ wt of THF, i.e. shear rate equal to $300 \mathrm{~s}^{-1}$, and the bath with the temperature set at $-0.6{ }^{\circ} \mathrm{C}$. The pressures used ranged from 10 bar to 100 bar. The viscosity results are presented in Figure 8. Again, it is noted that the higher torque transfer limit was obtained for almost all pressures, except for the test with the pressure equal to 10 bar, where we could observe that the steady state regime was achieved and a high viscosity plateau around $0.08 \mathrm{~Pa} \mathrm{~s}$ was obtained.

These tests also showed that the higher the pressure, the faster the torque transfer limit is reached, as the hydrates

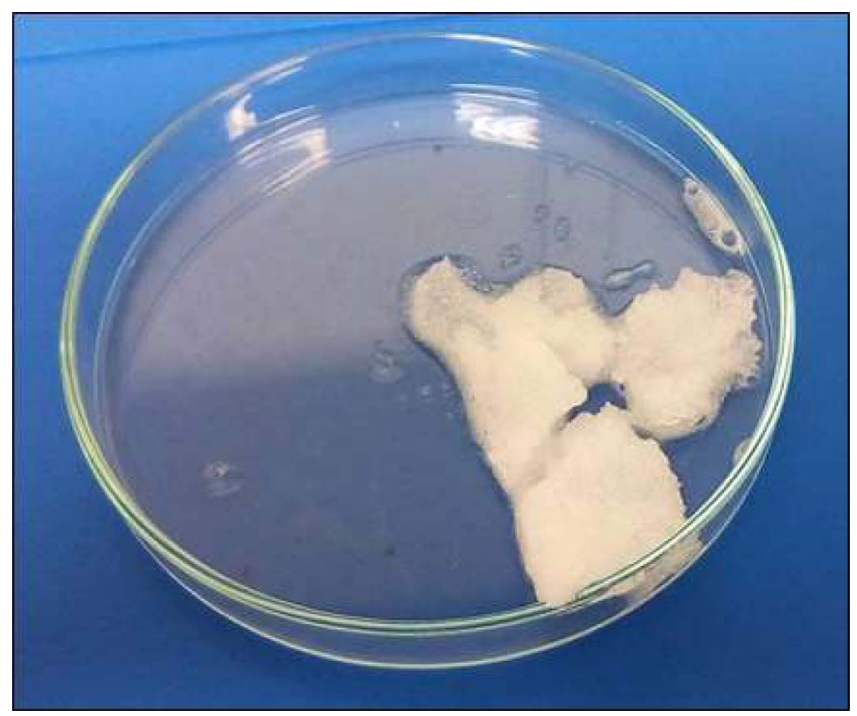

Fig. 7. Hydrate slurry of $30 \%$ wt of THF and nitrogen at 30 bar.

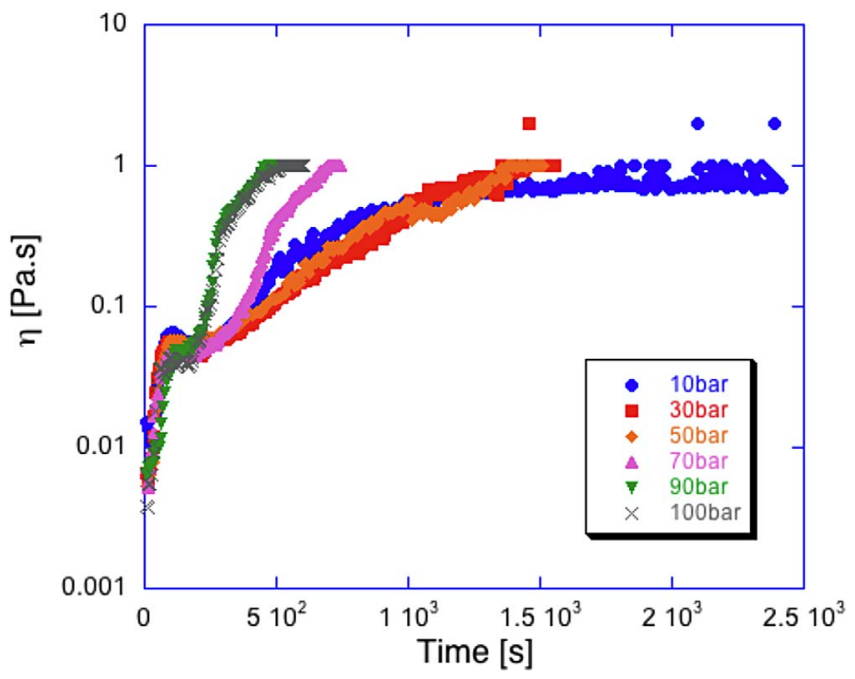

Fig. 8. Viscosity versus time for constant shear rate test $\left(300 \mathrm{~s}^{-1}\right)$ for $40 \%$ wt of THF, and pressure range of 10-100 bar.

form faster and the agglomeration of the crystals becomes more intense. Figure 9 shows the structure formed by hydrates of THF at a concentration of $40 \% \mathrm{wt}$, and pressurized with nitrogen at 30 bar.

The structure resembles the structure found with the mixture with a concentration of $30 \%$ wt of THF, but with an slightly excess amount of liquid THF. This large solid agglomerate was formed around and above the geometry, preventing the tests from being performed within the setted parameters.

The analysis were then performed with a mixture with larger concentration of THF. Figure 10 shows the viscosity as a function of time for constant shear rate tests for a mass concentration of THF equal to $50 \%$. The pressures used in these tests were equal to 1.2 bar (laboratory atmospheric 


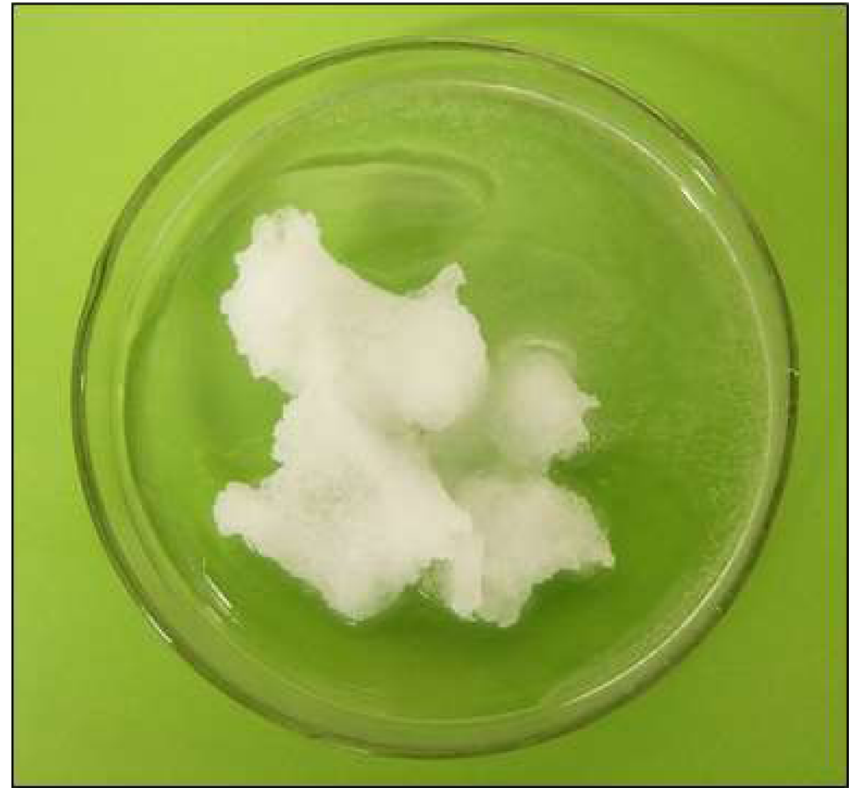

Fig. 9. Hydrate slurry of $40 \%$ wt of THF and nitrogen at 30 bar.

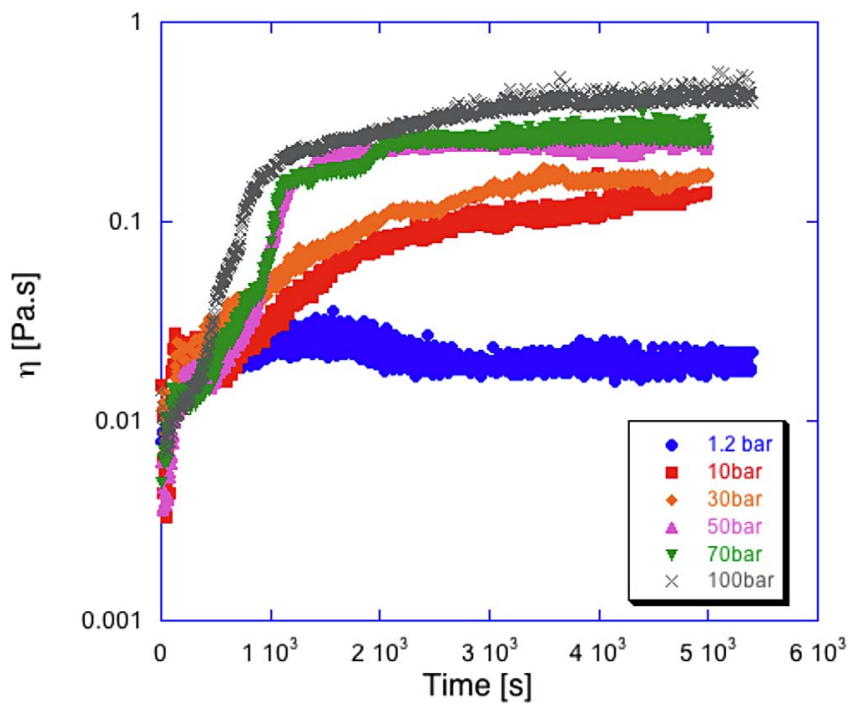

Fig. 10. Viscosity versus time for constant shear rate test $\left(300 \mathrm{~s}^{-1}\right)$ for $40 \%$ wt of THF, and pressure range of 5-60 bar.

pressure), 10 bar, 30 bar, 50 bar, 70 bar, and 100 bar. The results indicate that regardless of pressure, all tests were completed within the maximum torque limit, and the steady state regime was achieved. It can also be observed that the viscosity increases with the increase of pressure, as it is in general observed in liquids of constant composition. However, it is worth noting that in this case higher pressures are also leading to an increase of hydrates formed and agglomerated, so the final fluid composition is probably changing when the pressure changes. Moreover, the viscosity growth curve showed a larger slope for higher pressures, meaning that the hydrate formation is faster as the pressure

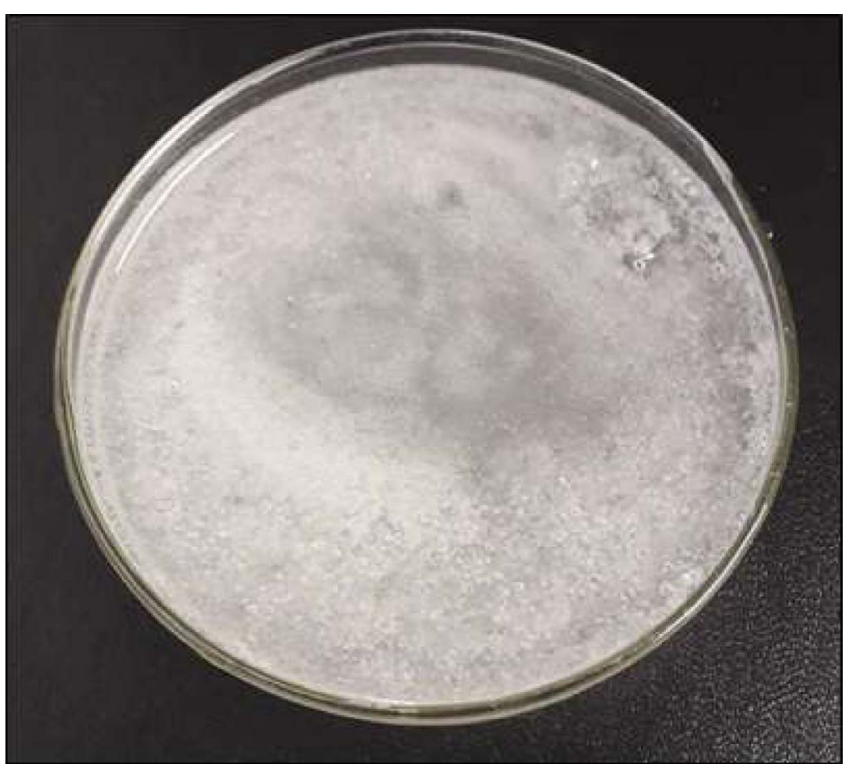

Fig. 11. Hydrates of 50\% wt of THF and nitrogen at 30 bar.

increases. Even at laboratory atmospheric pressure (1.2 bar), there was some hydrate formation, but the slurry viscosity was much lower than the hydrates slurries formed at higher pressures.

Figure 11 shows the hydrate structure formed with the mixture with the THF concentration of $50 \%$ wt, pressurized with nitrogen at 30 bar. As it can be seen, there is a large amount of liquid giving an appearance of gel-type material. In this case there is an excess of THF, with a large dispersion of hydrate crystals, and few agglomeration.

Several studies in the literature about the hydrates formation show that during the formation process the pressure value decreases [33, 37]. Thus, in the tests performed the pressure inside the cell was monitored to follow its evolution in time (Fig. 12). During the tests the temperature was also measured to verify hydrate dissociation and pressure stabilization. The results presented in Figure 12 were obtained for the test shown in Figure 10, for the mixture with $50 \%$ wt of THF, shear rate of $300 \mathrm{~s}^{-1}$, and pressure equal to 30 bar. The internal temperature of the pressure cell was equal to $1{ }^{\circ} \mathrm{C}$. As the time evolves, the pressure inside the cell drops, once the test is conducted at constant volume, and it stabilizes near 23 bar. During this first stage the temperature was kept constant and equal to $1{ }^{\circ} \mathrm{C}$. After $7200 \mathrm{~s}$, the temperature began to rise in a ratio of $2.4{ }^{\circ} \mathrm{C} / \mathrm{min}$, up to the final value of $25^{\circ} \mathrm{C}$. The shear rate was kept at $300 \mathrm{~s}^{-1}$ during the heating step. The pressure was reestablished, showing complete dissociation of the hydrates formed.

Figure 13 shows the evolution of viscosity and pressure over time, during the hydrate formation process for the $50 \%$ of THF, shear rate of $300 \mathrm{~s}^{-1}$, pressure set equal to $100 \mathrm{bar}$ and internal cell temperature equal to $1^{\circ} \mathrm{C}$. The large variation in the slope of the viscosity curve indicates the formation of hydrate crystals, which is accompanied by a reduction in pressure. This decrease in pressure is due to the nitrogen gas consumption during the process of the 


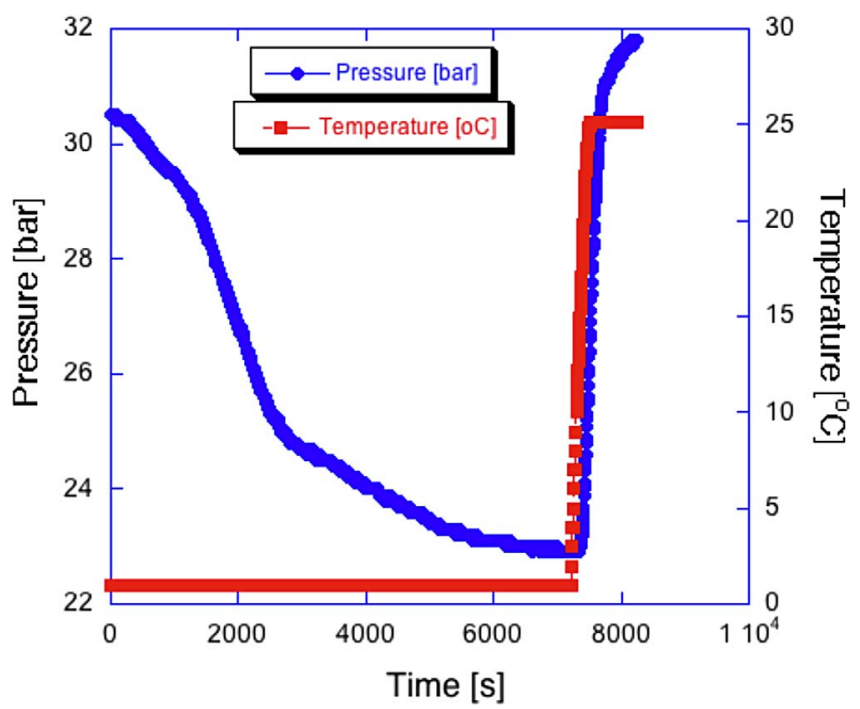

Fig. 12. Variation of pressure and temperature with time for THF $50 \%$ wt.

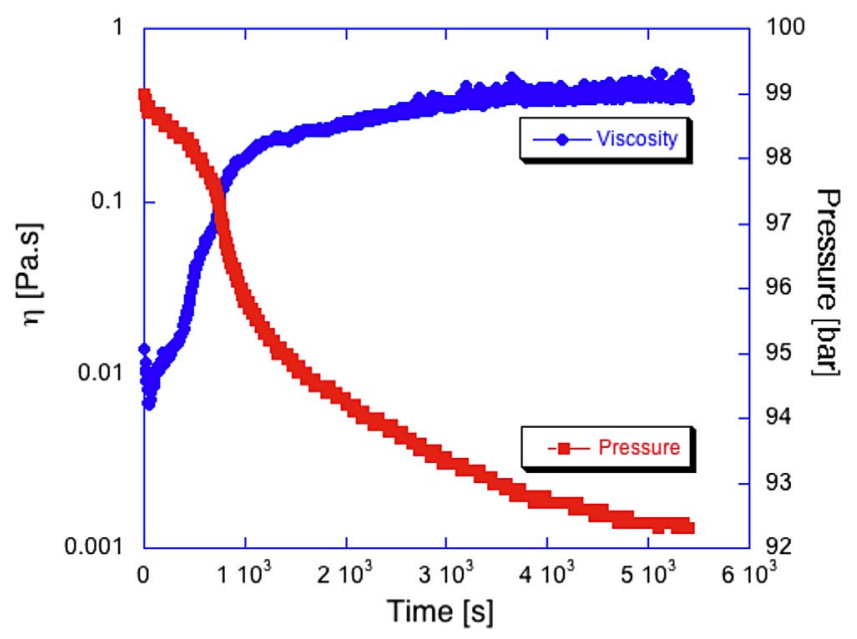

Fig. 13. Variation of viscosity and pressure with time for THF $50 \%$ wt, shear rate of $300 \mathrm{~s}^{-1}$, and pressure set equal to 100 bar.

hydrate formation. At the end of the test, both the pressure and the viscosity tend to a constant value, that of the final hydrate slurry at the established pressure.

Finally, Figure 14 shows the results of the oscillatory stress sweep tests. The hydrate slurry was pre-formed, using a concentration of THF $50 \%$ by mass. The temperature of the test was equal to $1{ }^{\circ} \mathrm{C}$, with the stress sweep starting at $1 \mathrm{~Pa}$ and going up to $100 \mathrm{~Pa}$. The frequency used in the tests was equal to $1 \mathrm{~Hz}$. An initial step was introduced to form the slurry, i.e. a constant pre-test step at $300 \mathrm{~s}^{-1}$ for $3600 \mathrm{~s}$ was performed to form the slurry.

Figure 14 shows the stress sweep results for the pressure equal to 10 bar, 50 bar, and 100 bar. Some initial values were discarded due to low torque values, below the minimum limit of $800 \mu \mathrm{Nm}$. All the results show a viscoelastic behavior up to a certain stress value, when the fluid is more

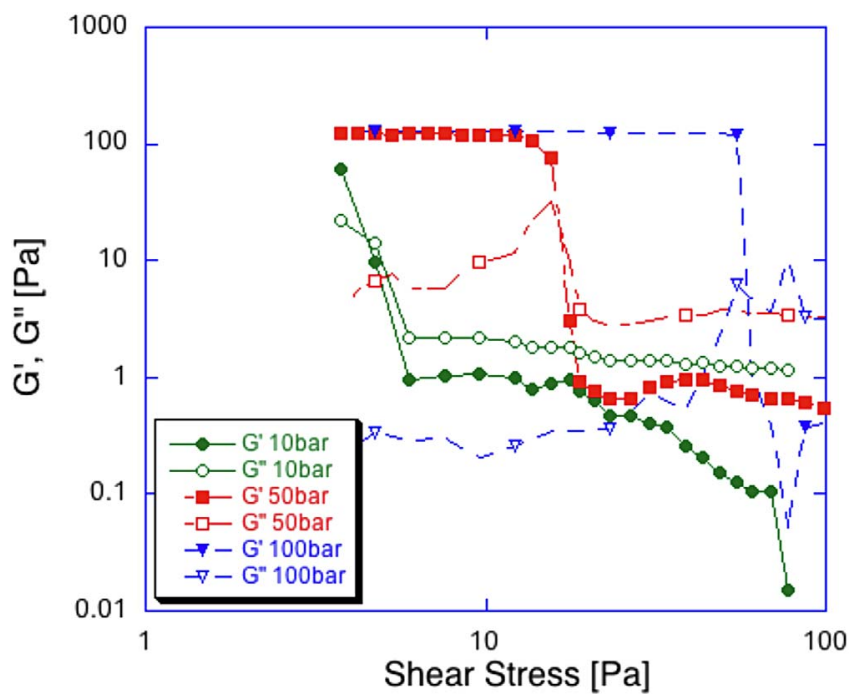

Fig. 14. Variation of viscosity and pressure with time for THF $50 \%$ wt and 100 bar.

structured. At the pressure of 10 bar, basically the crosspoint of the storage modulus $\left(G^{\prime}\right)$ and viscous modulus $\left(G^{\prime \prime}\right)$ occurred at the beginning of the test, indicating a low yield stress value, around $5 \mathrm{~Pa}$. However, at the 50 bar and 100 bar pressures, the crossing occurred at higher stress levels, as it was already expected due to the higher stiffness of the hydrate slurries formed. For the pressure of 50 bar the cross-point occurred around $15 \mathrm{~Pa}$, while for the pressure of 100 bar this crossing was around $53 \mathrm{~Pa}$. Such measurements can't be used as an accurate value of the slurry yield stress, but they can be used as an estimate of the value of this important rheological parameter.

\section{Final remarks}

The formation of hydrates slurries is one great issue in the oil and gas industry. They are usually formed in conditions of high pressure and low temperature and can strongly affect the flow inside pipelines. Therefore, knowledge of the rheology of these slurries is extremely important. This work presented some results of the rheology of THF hydrates slurries at higher pressures. Obtaining reliable results at these conditions is a difficult task per se. The tests performed show that the torque limits in the rheometers dramatically reduce the range of reliable data. Moreover, wall slip is an issue difficult to be considered inside the pressure cell. The rheological data showed the increase of the viscosity with the pressure. It has been also found that higher pressures tend to increase and accelerate hydrates formation. Oscillatory tests performed showed that the slurries have a yield stress, below which they present a viscoelastic behavior. All these results are in agreement with results obtained in field and loop tests. However, it is important to stress that rheological data obtained inside the rheometers result from more controlled experiments, so they can give important information about the formation 
P.H. de Lima Silva et al.: Oil \& Gas Science and Technology - Rev. IFP Energies nouvelles 75, 16 (2020)

and rheology of hydrates slurries. However, it must be pointed out that very careful experiments must be performed to obtain reliable data.

Acknowledgments. This work was possible due to the financial support of Petrobras, CNPq, CAPES, FAPERJ, FINEP, and MCT.

\section{References}

1 Carroll J.J. (2003) Natural gas hydrates: A guide for engineers, Elsevier Science, Amsterdam.

2 Sloan E.D., Koh C.A. (2008) Clathrate hydrates of natural gases, CRC Press, Boca Ratton, FL.

3 Sloan D., Koh C., Sum A., Ballard A.L., Creek J., Eaton M., Lachance J., Mcmullen N., Palermo T., Shoup G., Talley L. (2010) Natural gas hydrates in flow assurance, Gulf Professional Publishing, Oxford.

4 Babakhani S.M., Bouillot B., Ho-Van S., Douzet J., Herri J.-M. (2018) A review on hydrate composition and capability of thermodynamic modeling to predict hydrate pressure and composition, Fluid Phase Equilib. 472, 22-38.

5 Buzatoiu B., Popp V.V., Loas I.R. (1999) Hydrate problem in the oil production industry, in: Society of Petroleum Engineers (ed), International Symposium on Oilfield Chemistry, 16-19 February, Houston, TX. No. SPE 50749.

6 Jamaluddin A.K.M., Kalogerakis N., Bishnoi P.R. (1991) Hydrate plugging problems in undersea natural gas pipelines under shutdown condition, J. Petrol. Sci. Eng. 5, 323-335.

7 Makogon Y.F. (2010) Natural gas hydrates - a promising source of energy, J. Nat. Gas Sci. Eng. 2, 49-59.

8 Chatti I., Delahaye A., Fournaison L., Petitet J. (2005) Benefits and drawbacks of clathrate hydrates: A review of their areas of interest, Energy Convers. Manage. 46, 1333-1343.

9 Collett T., Bahk J.-J., Baker R., Boswell R., Divins D., Frye M., Goldberg D., Husebø J., Koh C., Malone M., Morell M., Myers G., Shipp C., Torres M. (2015) Methane hydrates in nature - current knowledge and challenges, J. Chem. Eng. Data 60, 319-329.

10 Javanmardi J., Nasrifar K., Najibi S., Moshfeghian M. (2005) Economic evaluation of natural gas hydrate as an alternative for natural gas transportation, Appl. Therm. Eng. 25, $1708-1723$.

11 Gudmundsson J., Borrehaug A. (1996) Frozen hydrate for transportation of natural gas, in: Second International Conference on Natural Gas Hydrate, 2-6 June, Toulouse, France, pp. 415-422.

12 Kvenvolden K. (1993) A primer on gas hydrates, United States Geological Survey, Reston, VA, pp. 279-292.

13 Boswell R., Collett T.S. (2011) Current perspectives on gas hydrate resources, Energy Environ. Sci. 4, 1206-1215.

14 Boswell R., Yamamoto K., Lee S.-R., Collett T., Kumar P., Dallimore S. (2014) Methane Hydrates. Future energy: Improved, sustainable and clean options for our planet, Elsevier, London, pp. 159-178.

15 Konno Y., Fujii T., Sato A., Akamine K., Naiki M., Masuda Y., Yamamoto K., Nagao J. (2017) Key findings of the world's first offshore methane hydrate production test off the coast of Japan: Toward future commercial production, Energy Fuels 31, 3, 2607-2616.

16 Koh C.A. (2011) Fundamentals and applications of gas hydrates, Annu. Rev. Chem. Biomol. Eng. 2, 237-257.
17 Zarinabadi S., Samimi A. (2011) Problems of hydrate formation in oil and gas pipes deals, J. Am. Sci. 5, 741-745.

18 Sloan E.D. (2005) A changing hydrate paradigm - from apprehension to avoidance to risk management, Fluid Phase Equilib. 228, 67-74.

19 Yao S., Li Y., Wang W., Song G., Shi Z., Wang X., Liu S. (2019) Investigation of hydrate slurry flow behaviors in deepsea pipes with different inclination angles, Oil Gas Sci. Technol. - Rev. IFP Energies nouvelles 74, 48.

20 Zhao J., Shi D., Zhao Y. (2012) Mathematical model and simulation of gas hydrate reservoir decomposition by depressurization, Oil Gas Sci. Technol. - Rev. IFP Energies nouvelles 67, 3, 379-385.

21 Lv X.F., Shi B.H., Wang Y., Tang Y.X., Wang L.Y., Gong J. (2015) Experimental study on hydrate induction time of gassaturated water-in-oil emulsion using a high-pressure flow loop, Oil Gas Sci. Technol. - Rev. IFP Energies nouvelles 70, $6,1111-1124$.

22 Cochran S. (2003) Hydrate control and remediation best practices in deepwater oil developments, in: Offshore Technology Conference, 5-8 May, Houston, TX. No. OTC 15255.

23 Fink J. (2016) Guide to the practical use of chemicals in refineries and pipelines, Gulf Professional Publishing, Oxford.

24 Daraboina N., Pachitsas S., Solms N.V. (2015) Natural gas hydrate formation and inhibition in gas/crude oil/aqueous systems, Fuel 148, 186-190.

25 Iida T., Mori H., Mochizuki T., Mori Y.H. (2001) Formation and dissociation of clathrate hydrate in stoichiometric tetrahydrofuran-water mixture subjected to onedimensional cooling or heating, Chem. Eng. Sci. 56, 16, 4747-4758.

26 Rueff R.M., Sloan E.D. (1985) Effect of granular sediment on some thermal properties of tetrahydrofuran hydrate, Ind. Eng. Chem. Process Des. Dev. 24, 3, 882-885.

27 Gough S.R., Davidson D.W. (1971) Composition of tetrahydrofuran hydrate and the effect of pressure on the decomposition, Can. J. Chem. 49, 16, 2691-2699.

28 Silva P.H.L., Naccache M.F., de Souza Mendes P.R., Campos F.B., Teixeira A., Sum A.K. (2017) Rheology of tetrahydrofuran hydrate slurries, Energy Fuels 31, 12, 14385-14392.

29 Austvik T. (1992) Hydrate formation and behavior in pipes, PhD Thesis, Norwegian University of Science and Technology, Trondheim, Norway.

30 Zhang H., Du J., Wang Y., Lang X., Li G., Chen J., Fan S. (2018) Investigation into thf hydrate slurry flow behaviour and inhibition by an anti-agglomeran, $R S C A d v$. 8, 22, 11946-11956.

31 Majid A.A.A., Wu D.T., Koh C.A. (2018) A perspective on rheological studies of gas hydrate slurry properties, Engineering 4, 3, 321-329.

32 Strauch B., Schicks J.M., Luzi-Helbing M., Naumann R., Herbst M. (2018) The difference between aspired and acquired hydrate volumes - a laboratory study of thf hydrate formation in dependence on initial THF: $\mathrm{H}_{2} \mathrm{O}$ ratios, $J$. Chem. Thermodyn. 117, 193-204.

33 Lv X., Shi B., Wang Y., Gong J. (2013) Study on gas hydrate formation and hydrate slurry flow in a multiphase transportation system, Energy Fuels 27, 12, 7294-7302.

34 Li Z.-Y., Xia Z.-M., Chen Z.-Y., Li X.-S., Xu C.-G., Yan R. (2019) The plateau effects and crystal transition study in tetrahydrofuran (THF) $/ \mathrm{CO}_{2} / \mathrm{H}_{2}$ hydrate formation processes, Appl. Energy 238, 195-201. 
35 Qin Y., Aman Z.M., Pickering P.F., Johns M.L., May E.F. (2017) High pressure rheological measurements of gas hydrate-in-oil slurries, J. Non-Newt. Fluid Mech. 248, 40-49.

36 Ahuja A., Zylyftari G., Morris J.F. (2015) Modeling oilfield emulsions: Comparison of cyclopentane hydrate an ice, Energy Fuels 29, 6286-6295.
37 Ahuja A., Zylyftari G., Morris J.F. (2015) Yield stress measurements of cyclopentane hydrate slurry, J. Non-Newt. Fluid Mech. 220, 116-125. 